\title{
Environmental Impact Assessment of Biogas Stations in the Czech Republic
}

\author{
Vladimír Lapčík ${ }^{1 *}$, Marta Lapčíková \\ ${ }^{1}$ VSB - Technical University of Ostrava, Faculty of Mining and Geology, 70833 Ostrava-Poruba, Czech Republic \\ ${ }^{2}$ Ministry of the Environment, Department of Public Service Practice IX, Čs. legii 5, 70200 Ostrava, Czech Republic \\ * Corresponding author: e-mail: vladimirlapcik@vsb.cz
}

\begin{abstract}
The article summarizes the authors' experience with environmental impact assessment in the branch of biogas plants. The introductory part of the paper describes the legislative obligations of the Czech Republic concerning the fulfilment of the European Union's limits as for the utilization of renewable energy resources. The next parts of the paper deal with an impact analysis of biogas plants on the environment. The final part of the paper deals with the experience concerning the implementation of the environmental impact assessment process in the field of biogas plants in the Czech Republic.
\end{abstract}

Keywords: Biogas station, environmental impact assessment, odour.

\section{INTRODUCTION}

From the legislative point of view, the required utilisation of energy from biogas stations is accounted for by the Czech Republic's duty to meet the European Union limits in the sphere of exploitation of alternative energy sources (Directive of the European Parliament and of the Council No 2001/77/EC of 27 September 2001, on the promotion of electricity produced from renewable energy sources in the home market with electricity).

The targets and conclusions of the above mentioned Directive 2001/77/EC, concerning the utilisation of renewable energy resources, were implemented into the State Energy Policy of the Czech Republic as well as the Act No 180/2005 Coll., on the promotion of electricity produced from renewable sources and amending some acts (Act on the promotion of renewable resource exploitation).

The implementation of biogas stations has a positive impact in meeting the targets making use of renewable energy sources, or fulfilment of the indicative target of a share of electricity from renewable resources on the gross electricity consumption in the Czech Republic in the amount of $13 \%$ as of 2020. Currently, within the European Union the percentage of energy from renewable resources is anticipated in the average amount of $20 \%$ in 2020 . Some countries expect higher shares of renewable energy (e.g. Sweden $49 \%$, Lithuania $42 \%$ ). Nevertheless, the above mentioned value of $13 \%$ (for the Czech Republic) is currently a discussion topic in the Czech Republic.

\section{BIOGAS STATIONS}

According to the processed substrate (biowaste, grown biomass), biogas stations (BGS) can be classified as follows ${ }^{1}$ :

- agricultural,

- sewage treatment,

- other.

\section{Agricultural BGS}

Agricultural biogas stations are such biogas stations that process the material of a plant character and dung, or bedding material. In such biogas stations it is not possible to process waste in accordance with Act No 185/2001
Coll., on waste, or other materials that come under Regulation of the European Parliament and the Council (EC) 1774/2002, on animal by-products. In the agricultural biogas stations, the following materials can be processed, in particular: animal materials (pig semi-liquid manure, pig dung with bedding material, cattle semi-liquid manure, cattle dung with bedding material, dung and bedding material from breeding of horses, goats and rabbits, poultry dejecta including bedding material, etc.), plant materials (straw of all types of cereal and oil plants, chaff and residues from cereal refining, potato haulm and peel, haulm from mangelwurzel and sugar beet, corn straw and grains, grass biomass or hay - haylage, non-feedable plant materials - ensilage, cereal, corn etc.) and grown biomass (cereal in lactic ripeness [whole plants] fresh and silaged, corn in wax ripeness [whole plants] fresh and silaged, ripe corn [whole plants] fresh and silaged, fodder cabbage [whole plants] fresh and silaged, "stick" biomass - chips or shreddings from deciduous woody plants of short rotation intensive cultures, etc.).

\section{Sewage treatment BGS}

Sewage treatment BGS process only sewage sludge and comprises an inseparable part of wastewater treatment plants. The technologies of anaerobic digestion are used for the purposes of anaerobic stabilization of the sludge formed in the wastewater treatment plants (WTPs). Those technologies are not designed to process biowaste or for waste disposal, but function as a part of WTP sludge management as a whole. No other materials than sludge from WTPs, septic tanks and cesspits or waste water get into this facility. In the case of another waste (under Act on Waste), which is added into tanks for anaerobic digestion, it is a case of an other biogas station (see below). The given facility is then subject to all requirements of Act on Waste and its implementing regulations. In biogas stations working in the WTP regime only there is no requirement for storage tanks for digested sludge. The technologies function in the wastewater treatment plant regime, whose working regulations include conditions for activated sludge handling and anaerobically stabilized sludge (digested sludge).

\section{Other BGS}

Biogas stations processing other feedstock may process biowaste stated in Table 3 of Appendix 2 of the relevant 
methodical directive of the Ministry of the Environment $(\mathrm{MoE})^{1}$. If BPS process animal by-products (ABP), they are subject to Regulation of the European Parliament and the Council (EC) 1774/2002 ${ }^{2}$ and must comply with the conditions therein, such as hygienization of waste or other feedstock (pasteurization, high-temperature hygienization).

A biogas station is a facility which makes use of renewable resources or organic waste (See above) for the production of biogas in the anaerobic way - fermentation. Biogas is entrapped and burnt in a part of a cogeneration unit with generation of electricity and heat. Apart from biogas, the output product of the anaerobic fermentation process is also digestate. With the digestate it is possible to separate solid components and liquid components. Both components are utilizable as fertilizers in the agriculture. After authorized certification of the digestate as a fertilizer, the digestate is no more considered as waste according to Act on Waste. However, until authorized biogas station certification of the digestate as a fertilizer, it is necessary to follow Act on Waste ${ }^{3}$ and, in particular, Decree of the MoE No 382/2001 Coll. ${ }^{4}$.

Table 1 states the composition of biogas from anaerobic fermentation that is combusted in a cogeneration unit.

Table 1. Biogas composition

\begin{tabular}{|l|c|}
\hline \multicolumn{1}{|c|}{ Component } & Volume percentage (\%) \\
\hline Methane $\left(\mathrm{CH}_{4}\right)$ & $40-80$ \\
\hline Carbon dioxide $\left(\mathrm{CO}_{2}\right)$ & $14-55$ \\
\hline Nitrogen $\left(\mathrm{N}_{2}\right)$ & $0-20$ \\
\hline Oxygen $\left(\mathrm{O}_{2}\right)$ & $0-2$ \\
\hline Hydrogen $\left(\mathrm{H}_{2}\right)$ & $0-1$ \\
\hline Ammonia $\left(\mathrm{NH}_{3}\right)$ & $0-1$ \\
\hline Hydrogen sulfide $\left(\mathrm{H}_{2} \mathrm{~S}\right)$ & $0-2$ \\
\hline
\end{tabular}

Units of Jenbacher (concern GE - See photo 1), MAN or Deutz companies are often used as compact cogeneration units. In principle, a cogeneration unit is made up by an internal-combustion engine (it has 12 or more cylinders) and a generator generating electric current (voltage of 0.4 $\mathrm{kV}$ and frequency of $50 \mathrm{~Hz}$ ).

For example, a cogeneration unit of GE Jenbacher JMS 412 GS-B.LC, which has a consumption of $403 \mathrm{~m}_{\mathrm{n}}{ }^{3}$ biogas per hour and is designed for biogas combustion with 50 to $65 \%$ methane content, has an electric output of $844 \mathrm{~kW}$ and a heat output of $789 \mathrm{~kW}$ (the heat output is usually higher than the electric one in case of older facilities ${ }^{5}$ ). The overall efficiency of cogeneration is $81 \%$, calorific efficiency of the facility is $39.1 \%$ and the electric one is $41.9 \%$ (See photo 1 - it is an older cogeneration unit of different parameters). The own consumption of electricity for the operation of a biogas station is approximately 5 to $6 \%$ out of the generated electric energy.

The given cogeneration unit is suitable for a biogas station that processes approximately below 30000 tons of biomass or biowaste per year.

\section{ENVIRONMENTAL IMPACT ANALYSIS OF BIOGAS STATIONS}

When assessing the environmental impact of biogas station projects the following factors must be taken into consideration ${ }^{5}$ :

- impact on the atmosphere,

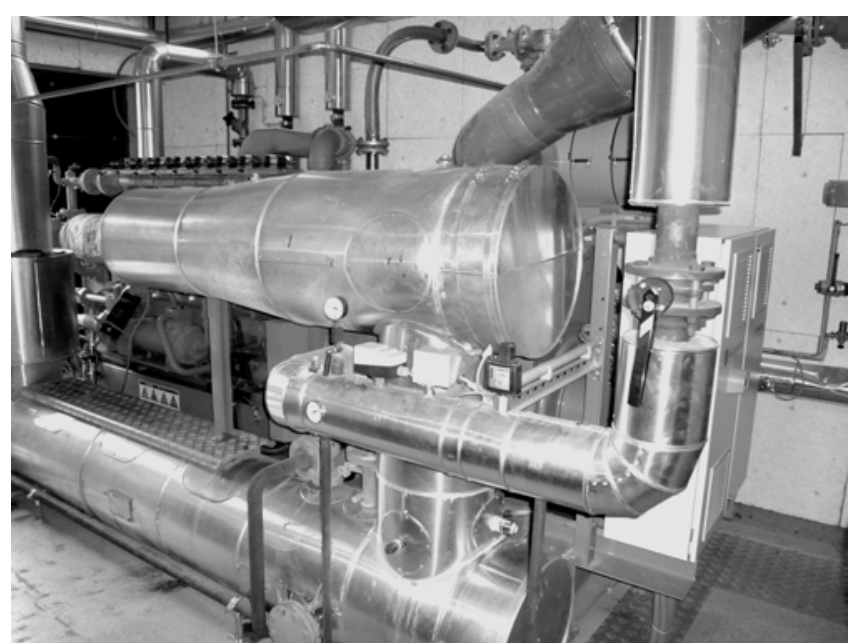

Photo 1. Cogeneration unit GE Jenbacher ${ }^{5}-$ photo by authors

- noise,

- impact on the surface and ground water,

- impact on the soil,

- impact on the landscape and face of the landscape,

- other impacts.

\section{Impacts on the atmosphere}

The major point source of pollution in a biogas station is a cogeneration unit combusting biogas. The quantity of emissions is negligible, in the majority of cases. In order to maximally reduce the negative impact on the atmosphere there is a desulphurization plant for the produced gas. To calculate the emissions from the operation of a cogeneration unit, emission limits for combustion sources - piston combustion engines - must be applied, the construction or conversion of which has been started after 17 May 2006 (article 2.B of Appendix 4) of Government Decree No 146/ 2007 Coll. ${ }^{6}$. In accordance with MoE Decree No 13/2009 Coll. ${ }^{7}$ no sulphur contents in the fuel have been determined for gases. Therefore, there is no emission limit for sulfur dioxide $\left(\mathrm{SO}_{2}\right)$ for stationary piston combustion engines (Government Decree No 146/2007 Coll.).

Among line sources of pollution there is transport of waste into the biogas station and transport of the produced fertilizers by trucks $(20 \div 25$ daily $)$ as well as the arrivals of cars driven by the crew and visitors (approx. 10 daily). The amount of emissions from transport is negligible.

It is odour which is assessed as one of the most disputable environmental impacts in biogas stations.

If only majority gases formed during anaerobic decomposition of organic compounds, such as methane, carbon dioxide or water vapour, there would be no problems with odour emissions. As this is not the case, the gaseous products from other biochemical processes arise, which produces the biogas's scent. Primarily, it is the matter of hydrogen sulfide, ammonia and other gases with negative odour effects. They are the chemical material composition at the entry into the fermenter, fermenter's operating parameters, method of storage and processing and further handling of the digestate, which are decisive for their formation. This implies that various types or kinds of biogas facilities jeopardise the surroundings with odour emissions of different intensity. 
The problems with odour mostly occur in older stations or more recent biogas stations that were established through reconstruction of the already existing facilities (e.g. of particular parts of agricultural premises). Such facilities predominantly comprise only one fermenter, a gasholder, pumped-storage reservoir, digestate's storage (in many cases it used to be a reservoir for semi-liquid manure) and cogeneration units. There is no hermetization of the technological equipment or other equipment to reduce odour substances (hermetization of the means of transport and handling). In this case the biogas yield is approximately $50 \%$.

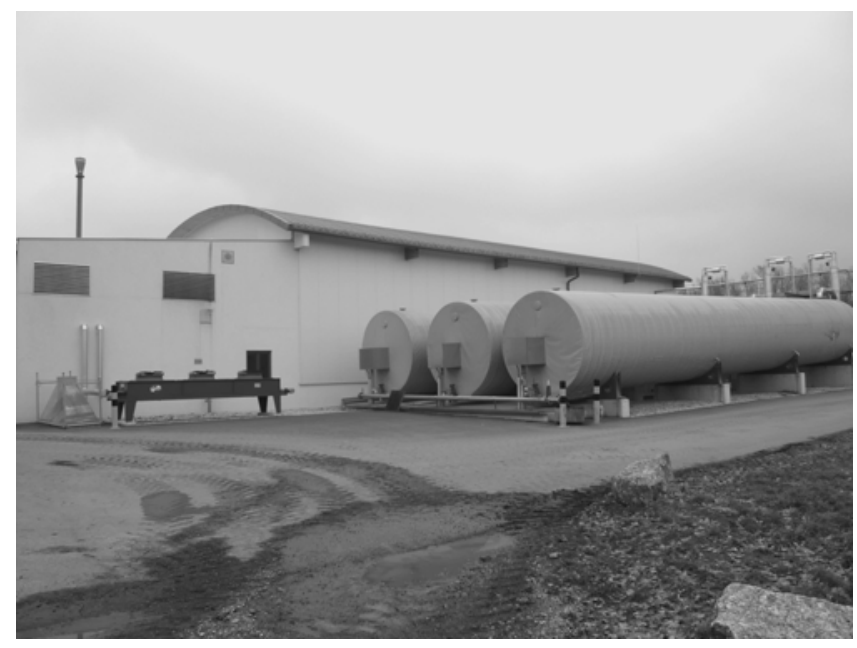

Photo 2. A view of steel tube fermenters ${ }^{8}$ (right part of photo) - BGS Amstetten (Austria) - photo by authors

On the contrary, technically advanced biogas stations ${ }^{9}$ that function with a biogas yield of as much as $95 \%$ mostly comprise of steel tube fermenters (See photo 2), concrete main fermenters, secondary fermenter, gasholder, digestate's storage (concrete reservoir which may be covered) and cogeneration units. Lumpy organic waste (grass and plant residues, semi-liquid manure, food leftovers and used fat, soil water, etc.) is mainly transported into an acceptance hall. These premises are enclosed and the exhausted air from the premises is conducted into a biological filter in order to remove the odour.

Waste hygienization, if necessary according to the requirements of a relevant European Union Regulation (Regulation of the European Parliament and the Council EC $1774 / 2002$ of 3 October 2002 - TNP - VO), is predominantly carried out in technically advanced facilities through heating up to the temperature of $70^{\circ} \mathrm{C}$ for one hour in the double-skin stainless vessels. Other possible methods of hygienization are stated in section $\mathrm{C}$ of Appendix 2 to Decree No 341/2008 Coll. ${ }^{\mathbf{1 0}}$.

The issue of odour emissions is subject to the provisions of Act No 86/2002 Coll., on the atmosphere protection, as amended. This act is followed by Decree No 205/2009 Coll., on the identification emissions from stationary sources and the execution of certain other provisions of Atmosphere Protection Act.

Own measuring of odours is handled by Decree No 362/ 2006 Coll., on the odour substance concentration determination methods, admissible levels of odour nuisance and its identification methods. The determination of odour substance concentration is carried out by course of $\S 2$ of the
Decree in stationary sources stated in the Appendix thereof, applying a procedure set by the Decree and a Czech technical norm of ČSN EN 13725. The final odour situation evaluation (mostly applying olfactometric measurement) must be executed within a test run.

The overwhelming majority of technically advanced biogas stations are not sources of significant odour emitted into the surroundings. Nevertheless, it must be pointed out that the working regulations of a biogas station must include a description of places of possible emergence of emissions of odour substances and a description of adopted technical-organizational measures to prevent their formation and to trap emissions of odour substances during an ordinary operation of the facility as well as during emergencies (See article 1, letter e) of Appendix 4 to Decree No 341/2008 Coll. ${ }^{10}$.

\section{Noise}

As for the technological noise of a biogas station it must be stated that its assessment is implemented by means of a noise study that evaluates noise at the nearest built-up area. With regard to a considerable distance from residential areas, the noise impacts are not significant. Moreover, a cogeneration unit is situated in a soundproof, insulated engine hall. The unit is of a compact version with an engine and generator placed on a flexible base plate. Other parts are an exhaust heat exchanger and an exhaust muffler.

The impact of the noise from transportation and its changes in relation with the construction and later operation of biogas stations show mainly during the daytime in the surroundings of the access road along where transport takes place. If the calculation points as for which the calculation of noise from stationary sources is carried out are often quite remote from the road, it is necessary to describe changes in the noise situation in the noise study through the changes in the equivalent noise levels in a standardized distance from the roads (e.g. $7.5 \mathrm{~m}$ from the axis of the nearest lane).

\section{Impact on the surface and ground water}

The implementation of a biogas station shall endanger neither surface nor ground water.

Process wastewater:

There is no process wastewater produced. After fermentation the digestate is processed and the service wastewater (permeate) is reused in the technological process. Its possible surplus can be applied anywhere as after the two-stage reverse osmosis the water quality shall be of satisfactory indexes for service water.

\section{Soil water:}

The arising soil water is mostly drained into a house wastewater treatment plant. The treated water is followingly conducted into an influent stream or the sewerage.

\section{Rainwater:}

Uncontaminated rainwater from the hall's roof is drained into an influent stream or storm-water drainage.

\section{Impact on the soil}

The construction sites of biogas stations are very often situated into wearing out agricultural premises, former industrial premises or the construction is designed on a "green field" within new industrial complexes. Even in the last case not much land gets occupied as, in the majority of 
cases, for the construction of a biogas station a sufficient piece of land is of 4 to 5 thousand $\mathrm{m}^{2}$.

At relevant processing, biogas station products (fertilizers) return nutrients back into the agricultural land. Therefore, it may be stated that an operation of a biogas station does not affect soil (if admittedly there is no unrestrained deposition of unprocessed digestate in thick layers onto the agricultural land, which sometimes happens, unfortunately).

The rock environment does not get affected by the assumed activities. The impact on mineral resources is not manifested either.

\section{Impact on the landscape and the face of the landscape}

In most cases, biogas stations do not influence the face of the landscape in the negative way as they are often situated in a locality where agricultural or industrial premises are situated. In the case of an alone construction, e.g. on an elevated place, an impact assessment study on the face of the landscape would be necessary.

\section{Other impacts}

Among other impacts it is possible to rank, for example, the issue of the land used for the application of liquid and solid digestate, details on the optimal or maximum quantities of the applied digestate, etc.

Nevertheless, it must be emphasized that in all the cases the production of fertilizers, which may be implemented in a commercial way, must be preferred to a mere application of the output substances from the fermentation process on the surrounding fields.

Note: A description of remediation digestate handling, including a specific handling method of digestate made during accidents or emergencies, must be incorporated into the working regulations of a biogas station (See article 1, letter e) of Appendix 4 to Decree No 341/2008 Coll., on details on biodegradable waste disposal).

The impacts on the fauna, flora and territorial system of ecological stability are negligible with regard to prevailing locations of biogas stations into already used agricultural or industrial zones.

\section{CONCLUSION}

As described above, in biogas stations it is the odour which is one of the most controversial environmental impacts. Certain legislative measures, either in the phase of preparation or already passed, aim to reduce odour emissions in the currently operated as well as the newly established biogas stations ${ }^{\mathbf{1 1}}$ :

- Methodical directive of the Ministry of the Environment (Department of Atmosphere Protection), on the conditions of biogas station approvals before being put into operation,

- Compulsory registration of the digestate as a fertilizer (by course of Act No 156/1998 Coll., on fertilizers, as amended),

- Determination of limit odour emission values for biogas stations, apart others,

- Price decisions of the Energy Regulatory Office (ERO) privileging agricultural biogas stations,

- Decree of the MoE No 362/2006 Coll., on the determination method of odour substance concentrations.
Unfortunately, the general public in the Czech Republic predominantly and automatically perceive biogas stations as potential sources of strong odour. This is explained by a historical experience when in the past only technologically imperfect biogas stations with no hermetization were established (mostly through reconstructions) and no further equipment to reduce odour substances, which led to high emissions of odour into the surroundings. Nowadays, it is very difficult to persuade the public that there are technologically advanced facilities that guarantee operations free of odour at concurrent high biogas yields.

In accordance with Appendix 1 to Act No 100/2001 Coll., on environmental impact assessment and amending some acts (Act on Environmental Impact Assessment), as amended, it is possible to classify the biogas station projects into category II (projects requiring rogatory proceedings) article 10.1 (Facility for storing, treatment and utilisation of hazardous waste; facility for physical-chemical treatment, energetic utilisation or disposal of other waste). The responsible authority to carry out the rogatory proceedings or the overall environmental impact assessment process is the relevant regional office.

If a rated useful heat of a facility (cogeneration units) shall be over $0.2 \mathrm{MW}$, the project is at the same time an under-limit project by course of article 3.1 (Facility for fuel combustion of a rated useful heat from 50 to $200 \mathrm{MW}$ ), category II of Appendix 1 to Act No 100/2001 Coll., as amended ${ }^{12}$. The responsible authority to make the decision whether fact-finding procedures will be necessary or not in case of an under-limit project (subject to amendment No 216/2007 Coll.) is the relevant regional office which may decide for the project to undergo the overall environmental impact assessment process in the following stages. At present, biogas stations projects are frequently classified into this category.

With regard to the above mentioned public attitude to biogas stations, the environmental impact assessment process for such facilities is protracted and problematic. In the majority of cases, the overall assessment process must be taken into account (an under-limit project notification processing or a notification by course of Appendix 3a or 3 to Act No 100/2001 Coll., as amended ${ }^{12}$, fact-finding procedures, documentation compilation, expert report elaboration, public hearing) despite the fact that the law hypothetically permits a mere notification of an under-limit project or subjects the project to fact-finding procedures only. This way, the officiating process is finished in the socalled accelerated proceedings or the project is not assessed at all (under-limit project).

\section{LITERATURE CITED}

1. Methodical directive No 12 of the Ministry of the Environment (Department of Atmosphere Protection), on the conditions of biogas station approvals before being put into operation. In: Bulletin of Ministry of the Environment, No 8, 2008, pp. 1-17.

2. Regulation of the European Parliament and the Council (EC) 1774/2002, on animal by-products.

3. Act No 185/2001 Coll., on waste (Czech Waste Act).

4. Decree of the Czech Ministry of the Environment No $382 / 2001$ Coll., on the conditions for treated sludge application in the agricultural land. 
5. Lapčík, V. (2009). Industrial Technologies and their Impact on Environment. (monograph). Ostrava, Czech Republic: VŠBTechnical University of Ostrava. FoMG. ISBN 978-80-2482015-6. 362 p. (in Czech).

6. Czech Government Decree No 146/2007 Coll., on emission limits and other conditions for an operation of stationary combustion sources of air pollution.

7. Decree of the Czech Ministry of the Environment No 13/ 2009 Coll., on the determination of requirements for stationary source fuel quality as for the protection of the atmosphere.

8. Bauer, F. (2007). Initial study - Biogas station Veřovice. Kemmelbach, Austria: Ing. Friedrich Bauer GmbH. 8 p.

9. Lapčík, V. (2009). Notification according to Act No 100/ 2001 Coll., as amended, of project "Biogas station Kostice". Ostrava. $82 \mathrm{p}$.

10. Decree No 341/2008 Coll., on details on biodegradable waste disposal.

11. Pastorek, Z. (2008). Biogas - useful energy source or risky way of enterprise. Alternative Energy (magazine), No 3, pp. 26-28. (in Czech).

12. Act No 100/2001 Coll., on environmental impact assessment and amending some acts (Act on Environmental Impact Assessment), as amended. 